\title{
A New Evaluation Method for Slope Stability Based on TOPSIS and MCS
}

\author{
Wenqiang Chen $\mathbb{D}^{1,2}$ Yufei Zhao ${ }^{1 D},{ }^{3}$ Lipeng Liu, ${ }^{3}$ and Xiaogang Wang ${ }^{3}$ \\ ${ }^{1}$ State Key Laboratory of Simulation and Regulation of Water Cycle in River Basin, \\ China Institution of Water Resources and Hydropower Research, Beijing, China \\ ${ }^{2}$ School of Management, Tianjin University of Technology, Tianjin, China \\ ${ }^{3}$ Geotechnical Engineering Department, China Institution of Water Resources and Hydropower Research, Beijing, China \\ Correspondence should be addressed to Wenqiang Chen; wenqiang205@163.com
}

Received 18 November 2019; Revised 19 January 2020; Accepted 28 January 2020; Published 19 February 2020

Academic Editor: Castorina S. Vieira

Copyright (c) 2020 Wenqiang Chen et al. This is an open access article distributed under the Creative Commons Attribution License, which permits unrestricted use, distribution, and reproduction in any medium, provided the original work is properly cited.

\begin{abstract}
Slope evaluation is a basic geotechnical engineering issue. The rationality of index weight greatly affects the accuracy of evaluation results in the evaluation system. Furthermore, in practical engineering, some indexes can be considered random variables obeying a certain distribution. Traditional evaluation methods of slope stability ignore the effect of this index uncertainty. Therefore, it is necessary to obtain the evaluation results of slope stability reasonably by modifying the previous weighting methods and considering the uncertainty values of the indexes. A new method has been introduced to solve the problem mentioned previously based on TOPSIS (Technique for Order Preference by Similarity to Ideal Solution) and Monte Carlo simulation (MCS). TOPSIS is used as a basic model for evaluating slope stability. TOPSIS and MCS are coupled to establish multiobjective optimization simulation model, which can search the more optimal and reliable weight. The optimal weight is then substituted into the TOPSIS basic model to calculate the status of slope stability. In this calculation process, MCS is introduced into the TOPSIS basic model to consider the uncertainty value of index. The new method of evaluating slope stability was demonstrated by taking a practical project as an example. Compared with other weighting methods, the coupled TOPSIS and MCS model can obtain the most reliable weight, and the reliability is $48.7 \%$. Then, the evaluation of slope stability was examined with the certainty and uncertainty cases, respectively. The results demonstrate that the proposed new evaluation method is more realistic than the traditional methods for evaluating the slope stability. The new method has high accuracy and is easy to use.
\end{abstract}

\section{Introduction}

Instabilities of natural and cut slopes cause enormous loss of life, injuries, and damage to the property in every year. Researchers have carried out a large number of evaluation studies for slope stability [1-5] in order to reduce the loss caused by slope sliding and save the cost of disaster prevention and reduction.

Generally, stability of slope is affected not only by quantifiable indicators (mechanics parameters, rainfall, slope height, etc.) but also by more qualitative indicators (geotechnical properties, slope morphology, fault development degree, etc.). Thereby, it is necessary to comprehensively consider the influence of quantitative and qualitative indexes on slope stability. At present, analytic hierarchy process (AHP) [6, 7], fuzzy mathematical method [8-10], grey clustering method [11], catastrophe theory [12], cloud model $[13,14]$, support vector machine $[15,16]$, and other "soft computing" methods have been widely used in evaluation of slope stability taking into account quantitative and qualitative indicators comprehensively. When using these methods to calculate the stable state of the slope, the weights of indicators must be determined. In addition, the rationality of index weight greatly affects the accuracy of evaluation results. Hence, it is important to determine the most reliable weights of indexes using these "soft computing" methods. Furthermore, the values of indexes are considered constant in these methods. 
Generally, some indexes can be considered random variables obeying a certain distribution, especially the cohesion and friction angle of rock. In practical engineering, a large number of mechanical tests and field surveys reveal uncertainty, particularly for the slope stability evaluation. However, the uncertainty of the indexes is not directly considered in the traditional methods. Therefore, it is necessary to obtain the evaluation of slope stability reasonably by modifying the previous weighting methods and considering the uncertainty values of the indexes, which needs further study.

The Technique for Order Preference by Similarity to Ideal Solution (TOPSIS), also known as ranking method approximating ideal solution, is a commonly used method for multiobjective decision analysis of finite solutions [17]. It is a powerful mathematical tool to solve the problem of multidimension indicators fusing. This method has been widely used in the field of slope engineering evaluation research. For example, Khakestar et al. [18] used TOPSIS for classifying each local block on the pit wall; Haghshenas et al. [19], based on fuzzy TOPSIS, made sorting and selection decisions on slope stability measures of rockfill dam; Wu et al. [20] proposed the coupling model of Monte Carlo simulation (MCS) and TOPSIS for the rock mass quality classification. This fully demonstrates the suitability of TOPSIS method in stability evaluation of slope. TOPSIS model is a mathematical method for solving classification problems [21]. Monte Carlo simulation (MCS) is an effective method to solve the problem of uncertainty and obtain the probability of some results, which generate random variables and substitute them into the solution model (basic model). MCS method has been widely used in the evaluation of slope stability. In this paper, MCS is employed to consider the uncertainty of the indexes, and TOPSIS is used as basic model in MCS. Hence MCS and TOPSIS are used to obtain the weights of indexes accurately and evaluate the slope stability effectively.

Therefore, to solve the problems detailed previously, a more application-quantitative method has been developed to evaluate slope stability based on TOPSIS and MCS. First, TOPSIS is used as basic model for evaluating slope stability. TOPSIS and MCS are coupled to establish multiobjective optimization simulation model, which can search the maximum reliability of weight. Then the optimal weight can be obtained by the weight optimization model. Afterwards the optimal weight is substituted into the TOPSIS basic model to calculate the stable state of slope. In this calculation process, MCS is introduced into the TOPSIS basic model to consider the uncertainty value of index. Last, the feasibility of this method is verified by taking a practical project as an example, and the probabilities of the evaluation results of slope stability are analyzed, considering the uncertainty of indexes.

\section{Construction of Evaluation Method for Slope Stability}

2.1. Technique for Order Preference by Similarity to Ideal Solution (TOPSIS). Our work tries to use TOPSIS as basic model in slope stability evaluation. Its basic principle about solving multitarget decision-making problems can be roughly described as follows [17, 22]:

(1) Construct and normalize the standard decision matrix

(2) Solve the indexes weight and compute the weighted normalized decision matrix

(3) Seek the Positive Ideal Solution (PIS) and Negative Ideal Solution (NIS)

(4) Calculate the distances from the investigated schemes to the PIS and NIS

(5) Calculate the ranking index, namely, the relative closeness of the investigated schemes with respect to the PIS, and then obtain the best optimal scheme and complete the evaluation on the investigated schemes

However, there are still some deficiencies in the TOPSIS method in terms of establishing standard decision matrix and calculating the relative closeness. Therefore, this paper improves the TOPSIS to ensure more stable and reliable evaluation results for slope stability.

2.1.1. Construction of the Standard Decision Matrix. Generally, the traditional TOPSIS method only ranked evaluation schemes, which makes it difficult to determine the PIS and the NIS. Therefore, we combine the grade standard of indexes with the evaluation schemes into a decision matrix. However, this is a flaw. That is, we need to solve the problem of inconsistency between the point value information form of the indexes in the evaluation schemes and the interval value information form of the grade standard of indexes. In this work, the smaller critical value in the grade interval of each index is selected to convert the point value information form. Then, the elements in the decision matrix all are point value information form. In this way, it is easy to determine the PIS and the NIS from the decision matrix. The PIS is the best value in the first grade of indexes, and the NIS is the worst value in the last grade of indexes.

Assuming that the number of index grade standards is $k$, the number of indexes is $n$. If the first index grade standard is expressed as $\left(\chi_{01}, \chi_{11}\right],\left(\chi_{11}, \chi_{12}\right],\left(\chi_{21}, \chi_{31}\right], \ldots,\left(\chi_{(k-1) 1}, \chi_{k 1}\right]$, then the values from 1 to $(k+1)$ in the first column of the decision matrix, respectively, are $\chi_{01}, \chi_{11}, \chi_{21}, \chi_{31}, \ldots$, $\chi_{(k-1) 1}, \chi_{k 1}$. If the number of evaluation schemes is $l-k$, then the number of rows in decision matrix is $m$ (where $m=k+1+l-k=l+1)$; the decision matrix can be described in the following formula: 


$$
\begin{aligned}
X & =\left[\begin{array}{cccc}
\chi_{01} & \chi_{02} & \ldots & \chi_{0 n} \\
\chi_{11} & \chi_{12} & \ldots & \chi_{1 n} \\
\chi_{21} & \chi_{22} & \ldots & \chi_{2 n} \\
\vdots & \vdots & \vdots & \vdots \\
\chi_{k 1} & \chi_{k 2} & \ldots & \chi_{k n} \\
\vdots & \vdots & \vdots & \vdots \\
\chi_{l 1} & \chi_{l 2} & \ldots & \chi_{\ln }
\end{array}\right] \\
& =\left[\begin{array}{ccccc}
a_{11} & \ldots & a_{1 j} & \ldots & a_{1 n} \\
\vdots & \vdots & \vdots & \vdots & \vdots \\
a_{i 1} & \ldots & a_{i j} & \ldots & a_{i n} \\
\vdots & \vdots & \vdots & \vdots & \vdots \\
a_{m 1} & \ldots & a_{m j} & \ldots & a_{m n}
\end{array}\right],
\end{aligned}
$$

where $X$ represents the decision matrix and $a_{i j}$ represents the $j^{\text {th }}$ index of the $i^{\text {th }}$ evaluation object, where $i=1,2,3, \ldots, m$; $j=1,2,3, \ldots, n$.

Because the dimension of indexes values is quite different, the decision matrix must be standardized for the convenience of calculations. The membership degree standardization method is used in this paper. The normalized decision matrix can be represented by $Z$, and the element $Z_{i j}$ of the matrix can be calculated by the following equations:

$$
\begin{aligned}
Z_{i j} & =\frac{a_{i j}-\min _{j}\left(a_{i j}\right)}{\max _{j}\left(a_{i j}\right)-\min _{j}\left(a_{i j}\right)} \text { (positive index), } \\
Z_{i j} & =\frac{\max _{j}\left(a_{i j}\right)-a_{i j}}{\max _{j}\left(a_{i j}\right)-\min _{j}\left(a_{i j}\right)} \text { (negative index), }
\end{aligned}
$$

where $a_{i j}$ represents an element of the standard decision matrix, where $i=1,2,3, \ldots, m$ and $j=1,2,3, \ldots, n$.

\subsubsection{Calculation of the Closeness Degree of the Evaluation} Objects. According to the TOPSIS method, if we know the weight of index $W=\left[w_{j} \mid j=1,2, \ldots, n\right]$, the weighting decision matrix $Y_{i j}$ can be calculated by using equation (4). The process calculation of the weight of index $W$ is detailed in the next section:

$$
Y_{i j}=w_{j} Z_{i j}
$$

Based on the weighting decision matrix $Y_{i j}$, we can obtain the PIS, that is, $x^{+}=\left(x_{1}^{+}, x_{2}^{+}, \ldots, x_{n}^{+}\right)$, and the NIS, that is, $x^{-}=\left(x_{1}^{-}, x_{2}^{-}, \ldots, x_{n}^{-}\right)$. Based on both the PIS and the NIS, the closeness degree from all the evaluation objects to the PIS and the NIS can further be calculated, respectively. The original TOPSIS method adopts Euclidean distance to measure the closeness degree; however, due to the specific linear correlation that usually exists between indexes, the application of Euclidean distance ceases to be reasonable [23]. This paper introduces cosine similarity to overcome the deficiency of Euclidean distance measurement. Cosine similarity, a distance measurement method of angle cosine, can calculate the distance of an evaluation object with respect to an ideal scheme [24]; that is, the smaller the angle between two vectors, the higher their similarity degree and the shorter the distance, and vice versa. Thus, cosine similarity can be employed to solve the distance $S_{i}^{+}$of the evaluation object $i$ with respect to $x^{+}$, as well as the distance $S_{i}^{-}$of the evaluation object $i$ and $x^{-}$, respectively:

$$
\begin{aligned}
& S_{i}^{+}=1-\frac{\sum_{j=1}^{n}\left(Y_{i j}-x_{j}^{c}\right) \times\left(x_{j}^{+}-x_{j}^{c}\right)}{\sqrt{\sum_{j=1}^{n}\left(Y_{i j}-x_{j}^{c}\right)^{2}} \times \sqrt{\sum_{j=1}^{n}\left(x_{j}^{+}-x_{j}^{c}\right)^{2}}}, \\
& S_{i}^{-}=1-\frac{\sum_{j=1}^{n}\left(Y_{i j}-x_{j}^{c}\right) \times\left(x_{j}^{-}-x_{j}^{c}\right)}{\sqrt{\sum_{j=1}^{n}\left(Y_{i j}-x_{j}^{c}\right)^{2}} \times \sqrt{\sum_{j=1}^{n}\left(x_{j}^{-}-x_{j}^{c}\right)^{2}}},
\end{aligned}
$$

where $i=1,2,3, \ldots, m, x_{j}^{c}=0.5\left(x_{j}^{+}+x_{j}^{-}\right)$.

Hence, calculate the ranking index, namely, the relative closeness of the evaluation object $i$ with respect to the PIS:

$$
C_{i}=\frac{S_{i}^{-}}{\left(S_{i}^{+}+S_{i}^{-}\right)},
$$

where $0 \leq C_{i} \leq 1$; if the evaluation object $i$ is the PIS, then $C_{i}=1$; if the evaluation object $i$ is the NIS, then $C_{i}=0$. It thus becomes clear that the higher the relative closeness of the evaluation object $i$ with respect to the PIS, the higher $C_{i}$, and vice versa.

2.2. TOPSIS and MCS Coupled Model of the Weight Optimization. The weights of all indexes are usually obtained using the expert evaluation method, the analytic hierarchy process (AHP), and other subjective weight methods [18]. The subjective weight methods are mostly based on the expert's personal experience and subjective judgment. To some extent, the influencing degrees of indexes cannot be objectively reflected. The objective weight methods can extremely embody data information of indexes, based on variation degree of index actual data, such as Gini coefficient method, entropy weight method, range method, and deviation maximization method [25]. Because these objective research methods need a large number of actual values of indexes, which results in some application limitations in the data collection, a substantial amount of research on synthesizing subjective and objective information has been conducted to improve the accuracy of decisionmaking. The basic theory of this weighting method is to minimize the deviation between the obtained combination weight and each basic weight and establish the target model according to the optimization goal [20].

As previously mentioned, many studies have focused on the weight determination methods to improve the accuracy of results. However, the weights of indexes are affected by the uncertainty of index actual data using the previous methods, which leads to instability of weights. To our knowledge, a few studies have investigated the reliability of weight. If the reliability of weight is higher, it means the evaluation result is more accurate. Thus, in this research work, TOPSIS and MCS are coupled to determine the optimal weights effectively. 
2.2.1. Establish Limit State Function. Given an index classification standard of slope, the number of index classification standards $k$ is five; the number of indexes $n$ is seven. Six sets of evaluation objects $\left(O^{7}, O^{8}, O^{9}, O^{10}, O^{11}\right.$, and $\left.O^{12}\right)$ can be generated based on random simulation, following the uniform distribution (the number of evaluation objects generated randomly is $k+1)$. Then, the standard decision matrix $Z=\left[Z_{i j} \mid i=1,2, \ldots, 12 ; j=1,2,3,4,5,6,7\right]$.

It is critical that each index data of the last five evaluation objects $\left(O^{8}, O^{9}, O^{10}, O^{11}\right.$, and $\left.O^{12}\right)$ comes from the same grade standard, respectively. The number of evaluation objects is equal to the number of index grading standards $k$. In other words, each index data of $O^{8}$ comes from the first grade randomly, following the uniform distribution $\left(\chi_{0 j}, \chi_{1 j}\right)$, each index data of $O^{9}$ comes from the second grade randomly, following the uniform distribution $\left(\chi_{1 j}, \chi_{2 j}\right)$, and so on. Therefore, the ranking indexes $C=\left[C_{i} \mid i=8,9,10,11,12\right]$ of $O^{8}, O^{9}, O^{10}, O^{11}$, and $O^{12}$ are known to be the constraints. The constraints are as follows:

$$
\left\{\begin{array}{l}
C_{2} \leq C_{8}<C_{1} \\
C_{3} \leq C_{9}<C_{2} \\
C_{4} \leq C_{10}<C_{3} \\
C_{5} \leq C_{11}<C_{4} \\
C_{6} \leq C_{12}<C_{5}
\end{array}\right.
$$

Moreover, each index data of the $7^{\text {th }}$ evaluation object $\left(O^{7}\right)$ comes from different grade randomly; thus the ranking index $C_{7}$ cannot directly judge the evaluation result. Cosine similarity can be employed to judge the evaluation result of $O^{7}$. Thus, $\operatorname{sim}\left(O^{7}, O^{8}\right), \operatorname{sim}\left(O^{7}, O^{9}\right), \operatorname{sim}\left(O^{7}, O^{10}\right), \operatorname{sim}\left(O^{7}\right.$, $\left.\mathrm{O}^{11}\right)$, and $\operatorname{sim}\left(\mathrm{O}^{7}, \mathrm{O}^{12}\right)$ can be calculated as

$$
\begin{aligned}
\operatorname{sim}\left(O^{7}, O^{i}\right) & =\frac{\sum_{j=1}^{7} O_{j}^{7} \times O_{j}^{i}}{\sqrt{\sum_{j=1}^{7}\left(O_{j}^{7}\right)^{2}} \times \sqrt{\sum_{j=1}^{7}\left(O_{j}^{i}\right)^{2}}} \\
i & =8,9,10,11,12 .
\end{aligned}
$$

If $\operatorname{sim}\left(O^{7}, O^{8}\right) \geq \operatorname{sim}\left(O^{7}, O^{8}\right)^{*}$, then $O^{7}$ and $O^{8}$ have the same result, and so on. According the definition of cosine similarity, it is easy to have a proposition.

Proposition 1. For evaluation objects $O^{i}, O^{j}$, and $O^{k}$, if $O^{i}$ and $O^{j}$ have the same evaluation result and $O^{i}$ and $O^{k}$ have different evaluation result, then $\min \left\{\operatorname{sim}\left(O^{i}, O^{j}\right)\right\}>$ $\max \left\{\operatorname{sim}\left(O^{i}, O^{k}\right)\right\}$.

Proof. Assume that $\min \left\{\operatorname{sim}\left(O^{i}, O^{j}\right)\right\} \leq \max \left\{\operatorname{sim}\left(O^{i}, O^{k}\right)\right\}$.

Then, $\operatorname{sim}\left(O^{i}, O^{j}\right) \geq \operatorname{sim}\left(O^{i}, O^{j}\right)^{*}$ and $\operatorname{sim}\left(O^{i}, O^{j}\right)^{*}<$ $\min \left\{\operatorname{sim}\left(O^{i}, O^{j}\right)\right\} \leq \max \left\{\operatorname{sim}\left(O^{i}, O^{k}\right)\right\}$.

Thus, $O^{i}$ and $O^{k}$ have the same evaluation result, which contradicts the proposition. Therefore, the proposition mentioned above is true.

Based on the proposition, we can determine the evaluation result of $O^{7}$ by calculating $\max \left\{\operatorname{sim}\left(O^{7}, O^{i}\right)\right\}, i=8,9$, 10, 11, and 12, as follows:

$$
\begin{cases}C_{2} \leq C_{7}<C_{1}, & \text { if } \max \left\{\operatorname{sim}\left(O^{7}, O^{i}\right)\right\}=\operatorname{sim}\left(O^{7}, O^{8}\right), \\ C_{3} \leq C_{7}<C_{2}, & \text { if } \max \left\{\operatorname{sim}\left(O^{7}, O^{i}\right)\right\}=\operatorname{sim}\left(O^{7}, O^{9}\right), \\ C_{4} \leq C_{7}<C_{3}, & \text { if } \max \left\{\operatorname{sim}\left(O^{7}, O^{i}\right)\right\}=\operatorname{sim}\left(O^{7}, O^{10}\right), \\ C_{5} \leq C_{7}<C_{4}, & \text { if } \max \left\{\operatorname{sim}\left(O^{7}, O^{i}\right)\right\}=\operatorname{sim}\left(O^{7}, O^{11}\right), \\ C_{6} \leq C_{7}<C_{5}, & \text { if } \max \left\{\operatorname{sim}\left(O^{7}, O^{i}\right)\right\}=\operatorname{sim}\left(O^{7}, O^{12}\right) .\end{cases}
$$

Obviously, if six sets of evaluation objects are generated randomly following the uniform distribution, the evaluation results of 6 sets of evaluation objects are known to be obeying the restrictions shown in equations (8) and (10).

For that reason, let us establish a limit state function $T_{k}$ $(k=1,2, \ldots, N)$ based on equations (7) and (9). Given $W=\left[w_{j} \mid j=1,2,3,4,5,6,7\right]$, substitute it into the TOPSIS basic model. Then the MCS method is conducted to calculate the reliability. If the test number is $N$ and the occurrence number of $T_{k}=1$ is $M$, then the reliability $P$ can be calculated by equation (12):

$$
\begin{aligned}
& T_{k}= \begin{cases}1, & \text { if } C_{i}(i=7, \ldots, 12), \\
0, & \text { otherwise. }\end{cases} \\
& \text { If } C_{i}(i=7, \ldots, 12) \text { satisfies equations }(8) \text { and }(10), \\
& \qquad P=\frac{M}{N} .
\end{aligned}
$$

2.2.2. Calculate the Optimal Weight $W$. Given $W=\left[w_{j} \mid j=1,2,3,4,5,6,7\right]$, if the value of reliability $P$ is maximum, it means the evaluation result is more accurate using this $W$ to calculate ranking index $C$. Thus, the optimal solution of $W$ will be obtained by finding the maximum probability $P$. Let is introduce an optimizing objective function of $W$ as follows:

$$
\max P(W)=\frac{M}{N} .
$$

Here, $W$ is $n$-dimensional vector; that is, $W=\left[w_{j} \mid j=1,2, \ldots, n\right] . W$ is decision variable.

In addition, we set constraints to obtain the optimum solution $W$ :

$$
\sum_{j=1}^{n} w_{j}=1 .
$$

Crystal Ball, an easy-to-use simulation program, can conduct Monte Carlo simulation (MCS) and estimate optimal values for the decision variables using the commercial OptQuest package, which all are associated with Microsoft Excel spreadsheet models [26]. Therefore, the previous steps can easily be implemented by Crystal Ball and can be set up in an Excel ${ }^{\circledR}$ worksheet. The OptQuest package bundled with Crystal Ball can be executed to obtain the maximized objective function, which calculates the optimal weight $W$ in an Excel spreadsheet.

In summary, the detailed procedure of weight calculation for slope stability (Figure 1) includes two parts: (1) give a 


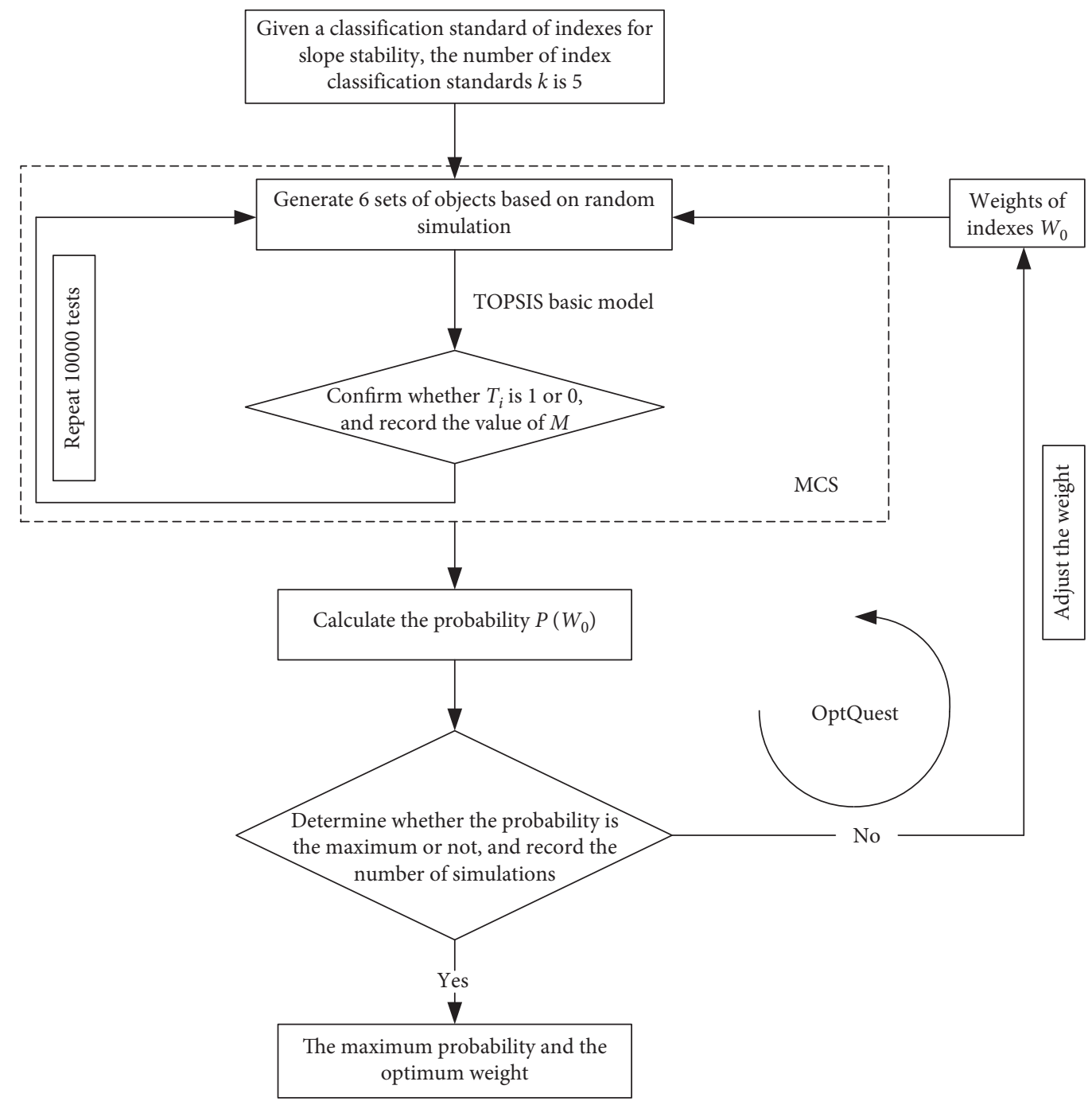

FIgURE 1: Basic flow chart of TOPSIS-MCS coupled model for calculating the weight $W$.

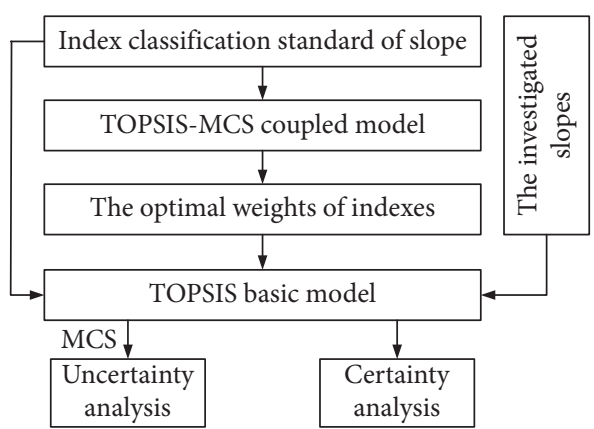

FIgURE 2: Basic flow chart for evaluating the slope stability with uncertainty and certainty analysis.

weight $W$ and calculate $P(W)$; (2) search the maximum $P(W)$ and obtain the optimum $W$.

2.3. Evaluate the Slope Stability. Using the optimal weight $W$, the evaluation of slope stability can be conducted using the TOPSIS basic model. However, some indexes can be

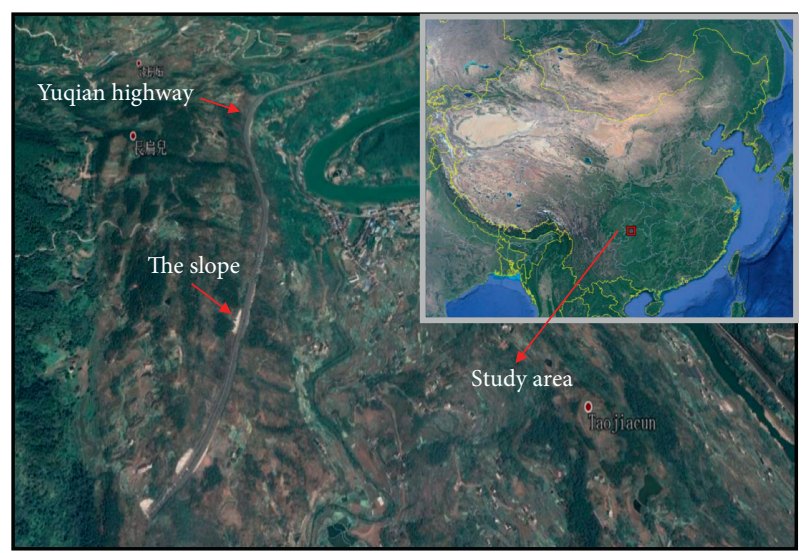

FIgURE 3: The geographical location of the study area (Google Earth, 2019).

considered random variables obeying a certain distribution. The uncertainty value of index is an important factor causing the inaccuracies of evaluation results. Unlike other evaluation methods for slope stability, MCS is introduced into the 
TABLE 1: Classification system of slope stability.

\begin{tabular}{|c|c|c|}
\hline Index & Grade & \\
\hline \multirow{5}{*}{$\begin{array}{l}\text { Rock quality designation (RQD) } \\
(\%)\end{array}$} & $100-90$ & I \\
\hline & $90 \sim 75$ & II \\
\hline & $75 \sim 50$ & III \\
\hline & $50 \sim 25$ & IV \\
\hline & $25 \sim 0$ & $\mathrm{~V}$ \\
\hline \multirow{5}{*}{ Joint occurrence of rock mass } & The dip direction of joints is opposite to that of slope $(90-100)$ & I \\
\hline & The trends of joints are perpendicular to the trends of slope $(75-90)$ & II \\
\hline & The trends of joints are consistent with those of slope but larger than dip angle of slope (50-75) & III \\
\hline & The trends of joints are consistent with those of slope but less than dip angle of slope $(30-50)$ & IV \\
\hline & $\begin{array}{l}\text { The trends of joints are consistent with those of slope but less than dip angle of slope, and there are } \\
\text { weak interlayers }(0-30)\end{array}$ & $\mathrm{V}$ \\
\hline \multirow{5}{*}{ Geo-stress (MPa) } & $0 \sim 2$ & I \\
\hline & $2 \sim 8$ & II \\
\hline & $8 \sim 14$ & III \\
\hline & $14 \sim 20$ & IV \\
\hline & $20 \sim 25$ & $\mathrm{~V}$ \\
\hline \multirow{5}{*}{ Cohesion $(c)(\mathrm{MPa})$} & $0.32 \sim 0.22$ & I \\
\hline & $0.22 \sim 0.12$ & II \\
\hline & $0.12 \sim 0.08$ & III \\
\hline & $0.08 \sim 0.05$ & IV \\
\hline & $0.05 \sim 0$ & $\mathrm{~V}$ \\
\hline \multirow{5}{*}{ Friction angle $(\varphi)\left({ }^{\circ}\right)$} & $45 \sim 37$ & I \\
\hline & $37 \sim 29$ & II \\
\hline & $29 \sim 21$ & III \\
\hline & $21 \sim 13$ & IV \\
\hline & $13 \sim 0$ & $\mathrm{~V}$ \\
\hline \multirow{5}{*}{ Slope height $(H)(\mathrm{m})$} & $0 \sim 30$ & $\bar{I}$ \\
\hline & $30 \sim 45$ & II \\
\hline & $45 \sim 60$ & III \\
\hline & $60 \sim 80$ & IV \\
\hline & $80 \sim 100$ & $\mathrm{~V}$ \\
\hline \multirow{5}{*}{$\begin{array}{l}\text { Daily maximum rainfall (DMR) } \\
(\mathrm{mm})\end{array}$} & $0 \sim 20$ & I \\
\hline & $20 \sim 40$ & II \\
\hline & $40 \sim 60$ & III \\
\hline & $60 \sim 100$ & IV \\
\hline & $100 \sim 150$ & $\mathrm{~V}$ \\
\hline
\end{tabular}

TOPSIS basic model to evaluate slope stability while taking into account the uncertainty value of index. The procedure for evaluation of slope stability based on TOPSIS and MCS is illustrated in Figure 2.

\section{Application of the New Method in Slope Stability Evaluation}

3.1. Engineering Background. The Yuqian Highway starts from Jiangbei District, Chongqing, China, extending to Qijiang District in the Southern part of Chongqing, China. The highway is $134 \mathrm{~km}$ long. There are 122 slopes over $20 \mathrm{~m}$ and nearly 60 slopes over $30 \mathrm{~m}$ along the whole Yuqian Highway [27]. The annual rainstorms make the high slopes unstable and finally triggered the mass sliding down, resulting in significant casualties and economic losses. The authors take a slope located between $\mathrm{K} 86+180$ and $\mathrm{K} 86+470$ of the Yuqian Highway as a typical example to conduct the slope stability, as shown in Figure 3. The slope has height of $46 \mathrm{~m}$ and angle of $64^{\circ}$. The geological characterization of slope is mostly sandstone in the top and mudstone in the bottom, consisting of weak layers in the middle. The rock stratum has trends of $55^{\circ}$ and dip angles of $23^{\circ}$. Rainfall is abundant in this area, which has adverse effect on the slope stability.

It is well known that slope stability is affected by both internal and external factors during slope cutting and other construction activities [28]. The internal factors mainly include rock type, geologic structure, hydrological conditions, geo stress, strength of rock, slope height, and slope angle, and the external factors include rainfall and human activities, such as rock blasting or cutting [29]. Based on geological surveys of the slope, previous studies [27], and Standard for Engineering Classification of Rock Masses of China (GB 50218-94) [30], all seven index parameters have been selected to classify the stability of slope, as shown in Table 1. In Table 1, all the indexes are divided into five grades, that is, stable, relatively stable, basically stable, relatively unstable, and unstable, corresponding to class I, class II, class III, class IV, and class V, respectively. 


\begin{tabular}{|c|c|c|c|c|c|c|c|c|c|c|c|c|c|c|c|c|}
\hline 4 & A & B & C & D & $\mathrm{E}$ & $\mathrm{F}$ & G & $\mathrm{H}$ & I & $\mathrm{J}$ & $\mathrm{K}$ & $\mathrm{L}$ & II & $\mathrm{N}$ & 0 & $\mathrm{P}$ \\
\hline 1 & & I & II & III & IV & V & $0^{7}$ & $O^{8}$ & $O^{9}$ & $O^{10}$ & $O^{11}$ & $O^{12}$ & Index & $W$ & $\operatorname{sim}\left(O^{7}, O^{8}\right)$ & 0.43 \\
\hline 2 & 100 & 90 & 75 & 50 & 25 & 0 & 1408 & 1000000 & 79791 & $\$ 1.241$ & 42.944 & 12992 & $R Q D$ & $x y$ & $\operatorname{sim}\left(O^{7}, O^{9}\right)$ & 0.60 \\
\hline 3 & 100 & 90 & 75 & 50 & 30 & 0 & $62: 11$ & 100000 & 55165 & 94.555 & 42164 & 5.000 & currence of ros: & $x \%$ & $\operatorname{sim}\left(O^{7}, O^{10}\right)$ & 0.75 \\
\hline 4 & 0 & 2 & 8 & 14 & 20 & 25 & 16.33 & 0.000 & $? 126$ & 13 658 & 14.633 & 23.421 & Geo stress & $\%$ & $\operatorname{sim}\left(O^{7}, O^{11}\right)$ & 0.82 \\
\hline 5 & 0.32 & 0.22 & 0.12 & 0.08 & 0.05 & 0 & 0.17 & 0.320 & 0.197 & 0116 & 0.080 & 0.003 & $C$ & \% & $\operatorname{sim}\left(O^{7}, O^{12}\right)$ & 0.82 \\
\hline 6 & 45 & 37 & 29 & 21 & 13 & 0 & 29.69 & 45000 & 33.059 & $28 \operatorname{sen} 8$ & 13.426 & 10.022 & $\varphi$ & mo & Classification $\mathrm{O}^{7}$ & 4 \\
\hline 7 & 0 & 30 & 45 & 60 & 80 & 100 & 1578 & 00000 & 38005 & 33.326 & 79423 & $\$ 4498$ & $H$ & $x y$ & $\sum w_{i}$ & 1 \\
\hline 8 & 0 & 20 & 40 & 60 & 100 & 150 & 1181 & 00000 & $230 \% 0$ & 43.359 & 55353 & 134.905 & $D M R$ & 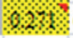 & Condition of constraints & 6000 \\
\hline 9 & \multicolumn{12}{|c|}{ the standard decision matrix $Z$} & & & & \\
\hline 10 & 0.000 & 0.100 & 0.250 & 0.500 & 0.750 & 1.000 & 0.859 & 0.000 & 0.202 & 0.488 & 0.571 & 0.870 & & & & \\
\hline 11 & 0.000 & 0.100 & 0.250 & 0.500 & 0.700 & 1.000 & 0.375 & 0.000 & 0.148 & 0.451 & 0.578 & 0.950 & & & & \\
\hline 12 & 0.000 & 0.080 & 0.320 & 0.560 & 0.800 & 1.000 & 0.653 & 0.000 & 0.285 & 0.548 & 0.585 & 0.937 & & & & \\
\hline 13 & 0.000 & 0.313 & 0.625 & 0.750 & 0.844 & 1.000 & 0.469 & 0.000 & 0.384 & 0.636 & 0.751 & 0.992 & & & & \\
\hline 14 & 0.000 & 0.178 & 0.356 & 0.533 & 0.711 & 1.000 & 0.340 & 0.000 & 0.265 & 0.363 & 0.702 & 0.777 & & & & \\
\hline 15 & 0.000 & 0.300 & 0.450 & 0.600 & 0.800 & 1.000 & 0.158 & 0.000 & 0.381 & 0.539 & 0.794 & 0.845 & & & & \\
\hline 16 & 0.000 & 0.133 & 0.267 & 0.400 & 0.667 & 1.000 & 0.787 & 0.000 & 0.154 & 0.289 & 0.572 & 0.899 & & & & \\
\hline 17 & \multicolumn{12}{|c|}{ the weighting decision matrix $Y$} & & & & \\
\hline 18 & 0.000 & 0.021 & 0.052 & 0.103 & 0.155 & 0.207 & 0.178 & 0.000 & 0.042 & 0.101 & 0.118 & 0.180 & & & & \\
\hline 19 & 0.000 & 0.019 & 0.048 & 0.096 & 0.135 & 0.192 & 0.072 & 0.000 & 0.029 & 0.087 & 0.111 & 0.183 & & & & \\
\hline 20 & 0.000 & 0.001 & 0.006 & 0.010 & 0.014 & 0.017 & 0.011 & 0.000 & 0.005 & 0.009 & 0.010 & 0.016 & & & & \\
\hline 21 & 0.000 & 0.049 & 0.098 & 0.117 & 0.132 & 0.156 & 0.073 & 0.000 & 0.060 & 0.100 & 0.118 & 0.155 & & & & \\
\hline 22 & 0.000 & 0.005 & 0.010 & 0.014 & 0.019 & 0.027 & 0.009 & 0.000 & 0.007 & 0.010 & 0.019 & 0.021 & & & & \\
\hline 23 & 0.000 & 0.039 & 0.058 & 0.077 & 0.103 & 0.129 & 0.020 & 0.000 & 0.049 & 0.069 & 0.102 & 0.109 & & & & \\
\hline 24 & 0.000 & 0.036 & 0.072 & 0.109 & 0.181 & 0.271 & 0.214 & 0.000 & 0.042 & 0.079 & 0.155 & 0.244 & & & & \\
\hline
\end{tabular}

FIGURE 4: The coupled TOPSIS and MCS model for calculating $W$ implemented in an Excel spreadsheet.

TABle 2: Data of the simulation model.

\begin{tabular}{lcccccc}
\hline Index & $O^{7}$ & $O^{8}$ & $O^{9}$ & $O^{10}$ & $O^{11}$ & $O^{12}$ \\
\hline RQD & $0-100$ & $90-100$ & $75-90$ & $50-75$ & $25-50$ & $0-25$ \\
Joint occurrence of rock mass & $0-100$ & $90-100$ & $75-90$ & $50-75$ & $30-50$ & $0-30$ \\
Geo-stress & $0-25$ & $0-2$ & $2-8$ & $8-14$ & $14-20$ & $20-25$ \\
$c$ & $0-0.32$ & $0.22-0.32$ & $0.12-0.22$ & $0.08-0.12$ & $0.05-0.08$ & $0-0.05$ \\
$\varphi$ & $0-45$ & $37-45$ & $29-37$ & $21-29$ & $13-21$ & $0-13$ \\
$H$ & $0-100$ & $0-30$ & $30-45$ & $45-60$ & $60-80$ & $80-100$ \\
DMR & $0-150$ & $0-20$ & $20-40$ & $40-60$ & $60-100$ & $100-150$ \\
\hline
\end{tabular}

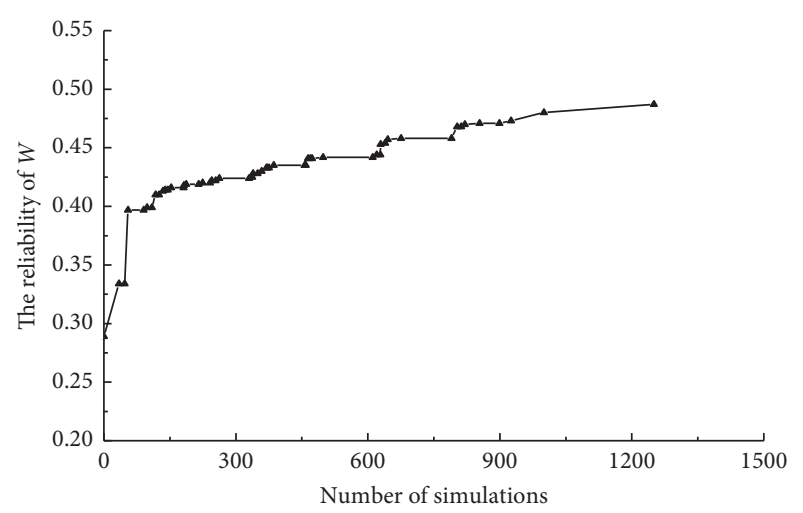

FIGURE 5: The reliability of $W$ obtained at different number of simulations.

3.2. Calculation of Weights. According to classification system of slope stability (Table 1), six sets of evaluation objects can be generated using stochastic simulation strategy. The standard decision matrix $Z$ can be constructed by equations (1)-(3), which is implemented in an Excel spreadsheet. We can set initial value for the weight $W$. Thus, the ranking index $C$ is obtained by equations (5) (7). The spreadsheet solution is shown in Figure 4.
The following section presents how to calculate the optimum weight $W$. We use Crystal Ball, which has built-in optimization system, OptQuest. OptQuest allows the model builder to bind the search space for the input parameters to set a maximum search length and to return the parameters combinations that meet the model criteria [31]. Subsequent steps are as follows:

(1) Enter equation (9) into the spreadsheet columns labeled $\operatorname{sim}\left(O^{7}, O^{8}\right), \operatorname{sim}\left(O^{7}, O^{9}\right)$, sim $\left(O^{7}, O^{10}\right)$, sim $\left(O^{7}, O^{11}\right)$, and $\operatorname{sim}\left(O^{7}, O^{12}\right)$, respectively. According to equation (10), we can determine the evaluation result of $O^{7}$, labeled evaluation $O^{7}$. The cell condition of constraints is equal to the number that satisfies the restrictions. If the number is six, the ranking index $C$ has satisfied the restrictions in equations (8) and (10), respectively. So, the cell condition of constraints is defined as objective. Now we want to find the maximum probability that the cell condition of constraints is equal to six.

(2) OptQuest tool is invoked to "maximized" cell objective, "by changing" the random variables cells G2: L8. The inputs and their corresponding distribution functions are displayed in Table 2. The decision variable is $W=\left[w_{j} \mid j=1,2, \ldots, 7\right]$. 
TABLE 3: Reliability comparison of different weight methods.

\begin{tabular}{|c|c|c|c|c|c|c|c|c|}
\hline Method & RQD & Geological characterization & Geo-stress & $c$ & $\varphi$ & $H$ & DMR & Reliability (\%) \\
\hline Dependent degree (Li et al. [27]) & 0.035 & 0.388 & 0.023 & 0.154 & 0.094 & 0.057 & 0.250 & 28.90 \\
\hline Over standard weighting & 0.075 & 0.231 & 0.004 & 0.181 & 0.183 & 0.101 & 0.225 & 29.42 \\
\hline The TOPSIS and MCS coupled model & 0.209 & 0.194 & 0.023 & 0.158 & 0.018 & 0.126 & 0.272 & 48.70 \\
\hline
\end{tabular}

TABLe 4: Actual data of index and evaluation results of slope stability.

\begin{tabular}{|c|c|c|c|c|c|c|c|c|c|c|c|}
\hline Case & $\begin{array}{l}\text { RQD } \\
(\%)\end{array}$ & $\begin{array}{c}\text { Joint occurrence } \\
\text { of rock mass }\end{array}$ & $\begin{array}{l}\text { Geo- } \\
\text { stress } \\
(\mathrm{MPa})\end{array}$ & $\begin{array}{c}C \\
(\mathrm{MPa})\end{array}$ & $\varphi$ & $\begin{array}{c}H \\
(\mathrm{~m})\end{array}$ & $\begin{array}{l}\text { DMR } \\
(\mathrm{mm})\end{array}$ & $\begin{array}{l}\text { Grey } \\
\text { correlation } \\
\text { analysis }\end{array}$ & $\begin{array}{l}\text { The new } \\
\text { method }\end{array}$ & $\begin{array}{c}\text { Grey correlation } \\
\text { analysis (the optimal } \\
\text { weights) }\end{array}$ & $\begin{array}{l}\text { Actual } \\
\text { status }\end{array}$ \\
\hline$a$ & 72 & 15 & 0.44 & 0.024 & 12 & 46 & 0 & $\mathrm{~V}$ & III & III & Stable \\
\hline$b$ & 72 & 15 & 0.44 & 0.024 & 12 & 46 & 75 & $\mathrm{~V}$ & IV & IV & Unstable \\
\hline$c$ & 72 & 15 & 0.44 & 0.024 & 12 & 46 & 120 & $\mathrm{~V}$ & IV & $\mathrm{V}$ & Unstable \\
\hline
\end{tabular}

TABle 5: Data input for the MCS.

\begin{tabular}{lccc}
\hline Index & Case 1 & Case 2 & Function \\
\hline DMR & $(0,120)$ & $(0,120)$ & Uniform distribution \\
$C$ & - & Mean, 0.024 & Normal distribution \\
& & Standard deviation, 0.5 & Mean, 12 \\
$\Phi$ & - & Standard deviation, 0.5 & Normal distribution \\
\hline
\end{tabular}

TABLe 6: Classification results of slope stability with the index uncertainties.

\begin{tabular}{lccccc}
\hline & I (\%) & II (\%) & III (\%) & IV (\%) & V (\%) \\
\hline Case 1 & 0.00 & 0.00 & 33.46 & 66.54 & 0.00 \\
Case 2 & 0.00 & 0.00 & 41.32 & 58.68 & 0.00 \\
\hline
\end{tabular}

(3) Select the constraints to limit the search to solutions that satisfy these restrictions shown in equations (8) and (10). Stop option is set to 1000 simulations and 1000 tests.

(4) Run the optimization model to display the progress of the search and to plot the best objective value for each simulation, as illustrated in Figure 5. At the completion of the optimization, the best solution is displayed. Figure 5 is generated automatically by OptQuest and updated after each simulation run to illustrate the progress of searching the best solution.

The optimal solution $W$ can be obtained automatically in Step 4 above. The results are shown in Table 3 . In order to compare the accuracy of weight $W$ obtained by different methods, Crystal Ball was used to calculate the reliability for performing Monte Carlo simulation (MCS). Some observations can be made based on the results presented in $\mathrm{Ta}-$ ble 3 . The reliability of $W$ obtained is $48.7 \%$ higher than the results obtained by other methods. Therefore, the coupled TOPSIS and MCS model for determining the weight of index is feasible in this paper. In fact, it is worth mentioning that the accuracy of $W$ will be improved if there are more reliable practical cases that can determine the evaluation results. The results also illustrate that the weight of DMR is larger than others. It is shown that rainfall has great influence on slope stability in Yuqian Highway, which is consistent with the actual situation.
3.3. Analysis Evaluation Results of the Slope Stability. According to the weight $W$ obtained in the previous section, the result of evaluation for the slope located between $\mathrm{K} 86+180$ and $\mathrm{K} 86+470$ can be calculated using the TOPSIS basic model. The other methods were conducted for comparison with the method proposed in this paper. The results are shown in Table 4.

As shown in Table 4, the evaluation results of the new method are consistent with the results of the grey correlation analysis for case $b$ and case $c$ but are different from the result of the grey correlation analysis for case $a$. The evaluation results of the new method are in good agreement with the actual status. Thus, the new evaluation method proposed is more accurate than the traditional method for evaluating the slope stability.

Table 4 also illustrates that if the value of DMR increases, the results of evaluation obtained by grey correlation analysis remain unchanged, but the results of evaluation obtained by the new method decrease. In order to verify the rationality of the optimal weights in slope stability evaluation, the optimal weights calculated in this paper are substituted into the grey correlation analysis to evaluate the slope stability. As can be seen in Table 4, the results are consistent with that of the new method, confirming the reliability of the optimal weights. In summary, compared to the other methods, the implementation process of the new method is more reliable, which is a simple and effective method to deal with classification or evaluation problems and has better practicability.

The system uncertainty is also caused by the uncertainty of parameters. Thus, the evaluation results of slope stability have uncertainty influenced by the uncertainty of parameters, such as $c, \varphi$, and DMR. The following section describes the effect of uncertainty of parameters on evaluation results, using the new method proposed by this paper. There are two cases for uncertainty analysis.

The uncertainties of one random variable (DMR, noted Case 1 ) and three random variables $(\mathrm{DMR}, c$, and $\varphi$, noted Case 2) are analyzed, respectively. The inputs and their corresponding distribution functions are displayed in $\mathrm{Ta}-$ ble 5 . The evaluation results of slope stability are illustrated in Table 6. 
As can be seen in Table 6, for Case 1, the probability at level I is $0.00 \%$, the probability at level II is $0.00 \%$, the probability at level III is $33.46 \%$, the probability at level IV is $66.54 \%$, and the probability at level $\mathrm{V}$ is $0.00 \%$. The results show that the value of standard deviation $f$ and the number of random variables are sensitive to the classification results. In summary, traditional slope stability evaluation methods are based on deterministic analysis, without considering the variability of indexes. The new method for evaluating slope stability can consider the variability of index in this paper, and the final evaluation results in the form of probability are convenient for further quantitative analysis.

\section{Summary and Conclusions}

This paper is devoted to developing a new reasonable method for evaluating slope stability based on TOPSIS and MCS. The new method mainly realizes the modification of the previous weighting methods and consideration of the uncertainty values of the indexes. It allows the evaluation of one or more objects that have multiple qualitative indexes and quantitative indexes, whether they are in the point value form or interval form. The important features of the new method include (1) combining the grade standard of indexes with the evaluation schemes into a decision matrix to determine the PIS and the NIS, (2) presenting a new optimization process for weight calculation based on coupling TOPSIS and MCS, (3) using Excel ${ }^{\circledR}$ worksheet and executing the OptQuest tool in the Excel to obtain the maximized objective function, which calculates the optimal weight, and (4) substituting the optimal weight into the TOPSIS basic model to evaluate the stability while taking into account the uncertainty of index by MCS.

The method has the advantage of avoiding the influence of subjectivity on index weights. In addition, the proposed evaluation method based on TOPSIS and MCS can take into account the uncertainty of the indexes and obtain the results in the probabilistic form. A case study of Yuqian Highway slope in southwestern China is used to verify the computational effect of the new method. Based on coupling TOPSIS and MCS, the proposed method determines more accurate weight for each evaluation index of the slope compared with other methods. Through calculation, we observe that the results of the new method are more similar to the real situations compared with the other methods and can obtain the probability of slope stability while taking into account the uncertainty of the indexes. Therefore, the proposed new method is more realistic and convenient than the traditional methods for evaluating the slope stability.

\section{Data Availability}

The data used to support the findings of this study are available from the corresponding author upon request.

\section{Conflicts of Interest}

The authors declare that they have no conflicts of interest.

\section{Acknowledgments}

This work was financially supported by the Open Research Fund of State Key Laboratory of Simulation and Regulation of Water Cycle in River Basin (China Institute of Water Resources and Hydropower Research), under Grant no. IWHR-SKL-201817.

\section{References}

[1] P. Budetta, "Assessment of rock fall risk along roads," Natural Hazards and Earth System Sciences, vol. 4, no. 2, pp. 71-81, 2004.

[2] Y.-C. Liu and C.-S. Chen, "A new approach for application of rock mass classification on rock slope stability assessment," Engineering Geology, vol. 89, no. 1-2, pp. 129-143, 2007.

[3] M. Pinheiro, S. Sanches, T. Miranda et al., "A new empirical system for rock slope stability analysis in exploitation stage," International Journal of Rock Mechanics and Mining Sciences, vol. 76, pp. 182-191, 2015.

[4] H. Basahel and H. Mitri, "Application of rock mass classification systems to rock slope stability assessment: a case study," Journal of Rock Mechanics and Geotechnical Engineering, vol. 9, no. 6, pp. 993-1009, 2017.

[5] T. B. D. Santos, M. S. Lana, T. M. Pereira, and I. Canbulat, "Quantitative hazard assessment system (Has-Q) for open pit mine slopes," International Journal of Mining Science and Technology, vol. 29, no. 3, pp. 419-427, 2019.

[6] J. Suh, Y. Choi, T.-D. Roh, H.-J. Lee, and H.-D. Park, "National-scale assessment of landslide susceptibility to rank the vulnerability to failure of rock-cut slopes along expressways in Korea," Environmental Earth Sciences, vol. 63, no. 3, pp. 619-632, 2011.

[7] S. H. Kil, D. K. Lee, J. H. Kim, M. H. Li, and G. Newman, "Utilizing the analytic hierarchy process to establish weighted values for evaluating the stability of slope revegetation based on hydroseeding applications in south Korea," Sustainability, vol. 8, no. 58, pp. 1-17, 2016.

[8] A. Daftaribesheli, M. Ataei, and F. Sereshki, "Assessment of rock slope stability using the fuzzy slope mass rating (FSMR) system," Applied Soft Computing, vol. 11, no. 8, pp. 44654473, 2011.

[9] H. J. Park, J.-G. Um, I. Woo, and J. W. Kim, “Application of fuzzy set theory to evaluate the probability of failure in rock slopes," Engineering Geology, vol. 125, pp. 92-101, 2012.

[10] W.-X. Li, D.-L. Qi, S.-F. Zheng, J.-C. Ren, J.-f. Li, and X. Yin, "Fuzzy mathematics model and its numerical method of stability analysis on rock slope of opencast metal mine," Applied Mathematical Modelling, vol. 39, no. 7, pp. 17841793, 2015.

[11] C. Li, S. Wu, Z. Zhu, and X. Bao, "The assessment of submarine slope instability in baiyun sag using gray clustering method," Natural Hazards, vol. 74, no. 2, pp. 1179-1190, 2014.

[12] K. Yang, T. Wang, and Z. Ma, "Application of cusp catastrophe theory to reliability analysis of slopes in open-pit mines," Mining Science and Technology (China), vol. 20, no. 1, pp. 71-75, 2010.

[13] A. J. Riquelme, R. Tomás, and A. Abellán, "Characterization of rock slopes through slope mass rating using 3D point clouds," International Journal of Rock Mechanics and Mining Sciences, vol. 84, pp. 165-176, 2016.

[14] M. Wang, X. Wang, Q. Liu, F. Shen, and J. Jin, "A novel multidimensional cloud model coupled with connection numbers 
theory for evaluation of slope stability," Applied Mathematical Modelling, vol. 77, no. 1, pp. 426-438, 2020.

[15] H.-b. Zhao, "Slope reliability analysis using a support vector machine," Computers and Geotechnics, vol. 35, no. 3, pp. 459-467, 2008.

[16] P. Samui, "Slope stability analysis: a support vector machine approach," Environmental Geology, vol. 56, no. 2, pp. 255267, 2008.

[17] C. L. Hwang and K. Yoon, Multiple Attribute Decision Making: Methods and Applications, a State of the Art Survey, Springer, New York, NY, USA, 1981.

[18] M. S. Khakestar, H. Hassani, P. Moarefvand, and H. Madani, "Application of multi-criteria decision making methods in slope stability analysis of open pit mines," Journal of the Geological Society of India, vol. 87, no. 2, pp. 213-221, 2016.

[19] S. S. Haghshenas, R. Mikaeil, and S. S. Haghshenas, "Fuzzy and classical MCDM techniques to rank the slope stabilization methods in a rock-fill reservoir dam," Civil Engineering Journal, vol. 3, no. 6, pp. 382-394, 2017.

[20] L. Z. Wu, S. H. Li, M. Zhang, and L. M. Zhang, "A new method for classifying rock mass quality based on MCS and TOPSIS," Environmental Earth Sciences, vol. 78, pp. 199-209, 2019.

[21] E. Roszkowska and D. Kacprzak, "The fuzzy saw and fuzzy TOPSIS procedures based on ordered fuzzy numbers," Information Sciences, vol. 369, pp. 564-584, 2016.

[22] T. Kuo, "A modified TOPSIS with a different ranking index," European Journal of Operational Research, vol. 260, no. 1, pp. 152-160, 2017.

[23] Z.-X. Wang and Y.-Y. Wang, "Evaluation of the provincial competitiveness of the Chinese high-tech industry using an improved TOPSIS method," Expert Systems with Applications, vol. 41, no. 6, pp. 2824-2831, 2014.

[24] H. Liao and Z. Xu, "Approaches to manage hesitant fuzzy linguistic information based on the cosine distance and similarity measures for HFLTSs and their application in qualitative decision making," Expert Systems with Applications, vol. 42, no. 12, pp. 5328-5336, 2015.

[25] G. Li and G. Chi, "A new determining objective weights method-gini coefficient weight," in Proceedings of the First International Conference on Information Science and Engineering 2009, pp. 3726-3729, Nanjing, China, December 2009.

[26] A. G. Gonzalez, M. A. Herrador, and A. G. Asuero, "Uncertainty evaluation from monte-carlo simulations by using crystal-ball software," Accreditation and Quality Assurance, vol. 10, no. 6, p. 324, 2005.

[27] K.-G. Li, K.-P. Hou, and W. Li, "Research on influence of factors dynamic weight on slope stability," Rock and Soil Mechanics, vol. 20, pp. 492-496, 2009.

[28] S. Lacasse, F. Nadim, and K. HoФeg, "Risk assessment and mitigation in geo-practice," in Proceedings of the Geotechnical Engineering State of the Art and Practice: Keynote Lectures from GeoCongress 2012, American Society of Civil Engineers, Oakland, CA, USA, March 2012.

[29] D. Lin, P. Chen, J. Ma et al., "Assessment of slope construction risk uncertainty based on index importance ranking," Bulletin of Engineering Geology and the Environment, vol. 78, no. 6, pp. 4217-4228, 2018.

[30] China Planning Press, The National Standards Compilation Group of People's Republic of China, GB/T50218-2014, Standard for Engineering Classification of Rock Masses, China Planning Press, Beijing, China, 2015, in Chinese.

[31] A. M. Al-Ahmari, "Solving stochastic machining economics problem using simulation optimization approach," Journal of
King Saud University-Engineering Sciences, vol. 22, no. 1, pp. 29-39, 2010. 